\title{
Manuscritos e incunables en el entorno de los Reyes Católicos: el cancionero Em6*
}

\author{
Manuscripts and Incunabula in the \\ Environment of the Catholic Kings: \\ The cancionero EM6
}

\section{Josep Llú́s MARTOS}

Departament de Filologia Catalana

Universitat d'Alacant

Carretera de San Vicente del Raspeig, s/n. Alacant, 0369o

jl.martos@va.es

Orcid ID 0000-0002-1379-7536

Resumen: Este trabajo estudia los datos externos e internos del cancionero EM6, lo que supone una importante novedad, al haber recibido muy poca atención codicológica. Este es, sin embargo, el punto de partida para una metodología que combina las técnicas historiográficas con las filológicas: la llamada filología material. Así, se analizan las diferentes secciones de este cancionero con criterios ecdóticos y filológicos, de lo que se concluye lo siguiente: a) el estadio textual de las Coplas de la vita Christi es inmediatamente anterior a su versión impresa y debe singularizarse frente al testimonio del cancionero SA4a; b) las obras que se copian a continuación presentan diferencias de orden, de duplicidad y de mutilaciones respecto del impreso de Centenera de 1483, pero son indudablemente un codex descriptus de este; c) se delimita y confirma la materia- lidad de los tres impresos cosidos tras el cancionero de Îñigo de Mendoza, cuya datación coincide con el periodo de Isabel como reina de Portugal; d) se determina que, como los tres impresos incorporados a este manuscrito, la copia del Repertorio de los tiempos proviene del incunable impreso por Fadrique de Basilea en 1493 y no del producido por Juan de Burgos en 1495. Como conclusión principal, se enmarca este cancionero en el entorno de los Reyes Católicos y se atribuye a Martín de Mendieta, un hombre de cámara de la reina y de la princesa Isabel, de cuyos libros personales custodia una parte unos años después de su muerte.

Palabras clave: Martín de Mendieta. Íñigo de Mendoza. Em6. Pliegos poéticos. Repertorio de los tiempos.

\footnotetext{
* Este trabajo se enmarca en el proyecto Cancionero, Romancero y Fuentes Impresas (FFI2017-86313-P)
} (AEI/FEDER, UE), del cual soy investigador principal. 
Abstract: This work studies the external data and the internal ones of the cancionero Em6, which is an important novelty, having received very little codicological attention. This is the text of the so-called philology. This is, however, the starting point for a methodology that combines historiographical techniques with philological ones: the so-called material philology. Thus, the different sections of this cancionero are analyzed with ecdotic and philological criteria, from which the following is concluded: a) The textual stage of the Coplas de la vita Christi is immediately before its printed version and should be singled out in front of the testimony of the cancionero SA4a; b) the works that are copied next have differences of order, of duplicity and of mutilations with respect to the print form by Centenera in 1483, but they are undoubtedly a codex descriptus of this; $c$ ) it is delimited and confirms the materiality of the three printed sewn after Înigo de Mendoza's cancionero, whose dating coincides with the period of Isabel as queen of Portugal; $d$ ) it is determined that, like the three printed forms incorporated into this manuscript, the copy of the Repertorio de los tiempos comes from the incunabulum printed by Fadrique de Basilea in 1493 and not the one produced by Juan de Burgos in 1495. As a main conclusion, this cancione$r o$ is framed in the environment of the Catholic Monarchs and is attributed to Martín de Mendieta, a chamber man of the queen and of the Princess Isabel, from whom he keeps part of her personal books a few years after her death.

Keywords: Martín de Mendieta. Íñigo de Mendoza. em6. Poetical Chap-books. Repertorio de los tiempos.

a atención codicológica que ha recibido el cancionero EM6 (Dutton I, 6669) ha sido muy limitada, ${ }^{1}$ al menos como volumen facticio global, y reducida, fundamentalmente, a la labor catalográfica de principios del siglo XX de la Real Biblioteca de El Escorial, donde se conserva, realizada por los padres agustinos Benigno Fernández y Julián Zarco: el primero de ellos, a través de excelentes datos publicados por entregas en la revista La Ciudad de Dios con una frecuencia sorprendente durante más de una década, y el segundo en su Catálogo de los manuscritos castellanos de la Real Biblioteca de El Escorial. En su catalogación discontinua de los incunables de esta biblioteca, Benigno Fernández (1904, 586-96) incluyó la descripción de este cancionero por su relación con dos de los impresos más tempranos de fray Íñigo de Mendoza -también conservados en este fondo, con las signaturas II-X-17 y 38-I-27-, pero, sobre todo, con $83^{\star} \mathrm{IM}$, el primer Cancionero incunable de fray Íñigo de Mendoza (Zamora: Centenera, c. 1483), que cataloga años después en esta misma revista (Fernández 1911, 56-60). En su descripción de EM6, Julián Zarco (II, 175-84) conoció y citó el trabajo previo de Fernández, reproduciendo literalmente buena parte del análisis catalográfico de la edición zamorana de Centenera (Fernández 1911).

1. Dutton mismo, de hecho, se limita a aportar el número de "303 folios" (I, 66) como único rasgo material, que, como veremos, proviene de la foliación, pero no del cómputo total de folios del cancionero. 
Los estudios de Keith Whinnom (1961, 1962 y 1977), en realidad, no buscan describir el cancionero, sino delimitarlo en cuanto al proceso de transmisión textual de la tradición manuscrita antigua y de los impresos incunables. De hecho, ni siquiera debió de consultar directamente el códice y sus datos provendrían del microfilm, ${ }^{2}$ si no del trabajo de Benigno Fernández (1904).

La Bibliografía española de textos antiguos (BETA) no analiza unitariamente el conjunto del cancionero, sino que lo divide en diferentes epígrafes, según las unidades codicológicas u obras que contiene: manid 3613, 3614, 1465. Incluso Julio Rodríguez-Puértolas (88-89), en su estudio y edición de las Coplas de la vita Christi de Íñigo de Mendoza, se limita a retomar los datos físicos de Zarco (II, 175-84), sin conocer los trabajos de Benigno Fernández y sin avanzar en la descripción codicológica estricta, aunque sí en la delimitación de la versión primitiva y en su relación con las otras dos posteriores (101-17). Y, desgraciadamente, ni siquiera An Electronic Corpus of 15th Century Castilian Cancionero Manuscripts ha prestado atención a este cancionero, a pesar de su amplio interés, derivado, en última instancia, de su carácter facticio y por recoger desde pliegos de testimonio único, hasta copias manuscritas de impresos perdidos u obras cuyo estadio textual es también único y, precisamente, el más cercano a la versión impresa.

La perspectiva externa del cancionero EM6 no ha requerido, por lo tanto, un interés especial, muy probablemente porque aquellos que lo han estudiado lo han hecho desde la tradición textual de sus versiones y han considerado suficiente la consulta de un microfilm, como debió de ocurrir sin duda en el caso de Whinnom (1961) y en el de Rodríguez-Puértolas, cuya sistematicidad en el desconocimiento directo de los testimonios de las Coplas de la vita Christi es evidente y evidenciado -por diferentes razones- en el estudio introductorio de su edición crítica. En definitiva, aunque sucintamente, tan solo Benigno Fernández (1904) y Julián Zarco (II, 175-84) describen, sensu stricto, el códice y lo hacen ambos a partir del original. ${ }^{4} \mathrm{El}$ primero, precediendo al

2. Whinnom $(1961,162)$ solo cuenta 233 folios manuscritos, un dato que se podría derivar de su consulta del microfilm antiguo que de este cancionero ofrecía El Escorial, que fue también la primera versión que se me envió y que llegaba hasta el inicio del primero de los pliegos sueltos. No hace mención del último impreso de EM6, ni de la copia manuscrita del Repertorio de los tiempos, que cierran el códice.

3. Aunque la entrada manid 1465 corresponde a EM6, no abarca el códice completo.

4. Ni siquiera BETA lo ha hecho, puesto que no incluyen ninguna inspección personal en las referencias bibliográficas. 
listado de obras, aporta los principales problemas de transcripción de cada una, así como las variantes de las ocho primeras coplas de la Vita Cbristi respecto de la tradición impresa, a partir de los ejemplares incunables de la Real Biblioteca de El Escorial..$^{5}$ Aunque Julián Zarco conoce y cita la referencia a la descripción de EM6 de Benigno Fernández, vuelve al manuscrito y corrige o aporta nuevos datos físicos. ${ }^{6}$

Todo ello evidencia, en definitiva, la precariedad científica en cuanto al conocimiento de este códice y la urgencia en atenderlo, lo que, sin lugar a dudas, justifica el objetivo principal de este trabajo, que consiste en el estudio de este cancionero desde la filología material para acabar contextualizándolo desde una perspectiva socioliteraria en el entorno más cercano de los Reyes Católicos.

\section{LOS DATOS EXTERNOS}

El cancionero EM6 se custodia, como indica esta sigla convencional de Brian Dutton, en la Real Biblioteca del Monasterio de El Escorial, con la signatura K-III-7. En el fol. 1r aparece tachada la referencia antigua III-I-25, que tuvo previamente en este mismo fondo. Asimismo, en la contraportada, encontramos 64-III-7 y III-K-7 -la primera a tinta azul, muy fina, y la segunda a tinta negra-, dos signaturas antiguas, aunque es cierto que la última es una varian-

5. "Ms. de letra de fines del siglo XV, que ocupa los folios 1 á 231 del códice III-K-7. En realidad, las hojas de que consta son 233 , pues se hallan repetidos en la foliatura los números 29 y 116. Su tamaño es en $4 .^{\circ}$, de 212 x $150 \mathrm{~mm}$., y se halla encuadernado con otras obras en un volumen en pergamino, con el rótulo FR. INIIGO LÓPEZ DE MENDOZA, de letra relativamente moderna. También en la primera hoja de texto del Cancionero, que describiremos en el número siguiente, se ve escrito, de letra del siglo XVI, el apellido Mendoza, precedido por mano posterior de las palabras Fr. Iñigo López. Estas notas, de autoridad muy discutible, debieron inducir á Amador de los Rios á adoptar los dos apellidos, no obstante que los mss. é impresos antiguos guardan completo silencio respecto del primero. En una hoja blanca que va después del fol. 237 se leen los nombres de Martín de Mendieta y de María (¿) de Ugalde, que serían los poseedores primitivos de este códice, cuya entrada en la Biblioteca es muy posterior al siglo XVI. Con el Cancionero de Fr. Iñigo están encuadernados en el mismo volumen un pliego impreso, muy mal tratado, con las Coplas al Nacimiento de N. Señor, anónimas, pero de Fray Ambrosio Montesino; otro pliego, también impreso, que contiene la Epistola de S. Bernardo á Raimundo; y, por último, una copia del Repertorio de los tiempos, de Andrés de Li" (Fernández 1904, 586).

6. "Sign. ant.: iij.I.25. 303 hs. de papel, ff. a lápiz, con num. arábiga. Los folios 29 y 116 están repetidos en la numeración. Letra de fines del s. XV, a plana entera y a 2 cols. Filigrana: un aspa de S. Andrés. Caja total: 215 x $150 \mathrm{~mm}$. Enc. en perg. Lomo: «Fr. Iñigo Lopez (asi) de Mendoza». Al fol. 303 hay una subscripción tachada. En el fol. $1 a$, margen inferior, se lee: «De la libreria de s. Hj[eroni]mo de sal[amanc]a», de letra del s. XVII" (Zarco II, 175). 
te de la actual, que aparece copiada doblemente abajo. De hecho, no solo debe de ser inmediatamente anterior, sino muy reciente, como se deriva de que Benigno Fernández $(1904,586)$ la dé todavía como referencia en marzo de 1904. Julián Zarco (II, 175-84), sin embargo, ya lo refiere como K.III.7 dos décadas después.

La anotación de mano del siglo XVII que encontramos en el margen inferior del fol. 1r localiza el códice con anterioridad en el Monasterio de los Jerónimos de Salamanca. Al final del cancionero, en el fol. 303v, hay otros exlibris, el más importante de los cuales, desgraciadamente, se ha tachado. Sí que podemos recuperar de ellos la referencia al "Muy poderoso mj señor pero de mendoza" o "De la muy noble ciudad de Ocaña". Avanzado el volumen y, probablemente, afectando el ex-libris solo a una sección del facticio, se indica que "Este libro es de Martín de Mendieta...". Junto a este y cancelado en parte, se puede ver escrito "[...]rin de Vgalde" (f. 237bis v), con el principio del nombre cancelado con tinta.

El códice presenta una encuadernación en pergamino de tres nervios internos al lomo, que reunió las secciones de este cancionero en una fecha antigua, posterior a la copia de los textos que contiene, pero probablemente cercana a la de los impresos incorporados, c. 1497-1498. Es un volumen de papel plegado in quarto, que contiene 307 folios, con foliación moderna en arábigos y a lápiz, que, en realidad, llega solo hasta el fol. 303, porque no se numeran los posteriores a los fols. 29 y 116, ni tampoco los dos que quedan en blanco que rematan el impreso $99^{*} \mathrm{RN}$. Los incunables que contiene EM6, por lo tanto, también se incluyen en esta foliación. Se han guillotinado en exceso los folios, lo que afecta al texto de los últimos cuadernos por su margen lateral. Gracias a que el lomo está despegado y la contracubierta se encuentra separada del cosido, se puede comprobar que, para unificar el engrudo y reforzar la encuadernación, se usó un folio manuscrito con letra antigua, probablemente del siglo XIII.

Hay claras evidencias de que el libro ha tenido un uso frecuente y continuado a través de los siglos, como demuestran, entre otros aspectos, las numerosas anotaciones, ${ }^{7}$ de manos diferentes; de hecho, un corrector moderno resuelve a menudo algunos problemas de copia: "Dos coplas" (f. 33v) [a lápiz];

7. El códice en general, de hecho, está repleto de probationes calami y dibujos, como ocurre, por ejemplo, en los ff. 21r, 117v-118r y 119. En el fol. 237bis $r$ se encuentran dos figuras antropomórficas dibujadas, de un hombre y una mujer. 
"/fol. 3/" (f. 34r) [a lápiz]; "Sigue en el fol. 91" (f. 89v) [a lápiz]; "Pasa al fol. 93" (f. 90v) [a tinta]; "Pasa al fol. 92" (f. 93v) [a tinta]; "Sigue en el fol. 91" (f. 89v) [a lápiz]; "Pasa al fol. 93" (f. 90") [a tinta]; "V. al fol. 225v un texto más puro de esta composición" (f. 112r) [a tinta negra y más fino trazo]; [marca inicial de cambio] "Justa de la razón, estrofa 4." (f. 117r) [a tinta marrón]; "Los gozos" (f. 121r) [a tinta marrón]; [marca inicial de cambio] "de una composición anterior" (f. 124v) [a tinta marrón, la misma en los tres últimos casos]; etc. Indica al inicio del códice que "Cerca del fin de este tomo está el Reportorio de los tiempos" (f. 1r) y también corrige lecciones, como ocurre en el fol. $74 \mathrm{v}$, donde subraya el último verso y bajo de "toda perdida" pone "y en el madero".

Más allá de la mutilación de fragmentos de folio o de su mal estado -como ocurre en los fols. 1, 121, 164, 192, 196, 203, 207, 215, 220, 227, 234 y $236-$, tenemos constancia de que se han perdido dos hojas de $99^{*} \mathrm{RN}$. De hecho, todos los folios de este impreso quedan sueltos, cosidos entre sí muy precariamente con un hilo fino a manera de zurcido improvisado, como si se tratase de tela en vez de papel. El fol. 233 está desgarrado en la parte superior, pero se cose a la siguiente hoja del impreso. Mediante una gran cantidad de engrudo, se unifican y se pegan al lomo. Los folios perdidos son anteriores a la foliación y es lógico pensar que hubieran desaparecido una vez incorporado el pliego al códice. De hecho, el cosido posterior ante la desencuadernación parece indicarlo así. El pliego suelto del Pseudo Bernardo, que sigue a este, también se cose, en este caso, al cuaderno manuscrito que contiene el inicio del Repertorio de los tiempos, en una restauración improvisada que forma parte del mismo proceso aplicado al impreso $99^{*} \mathrm{RN}$.

Keith Whinnom delimita paleográficamente el códice, con una cierta vagedad, menor, sin embargo, que la de Fernández y la de Zarco: "El MS. es obra de más de una mano, aunque no es fácil determinar cuántas intervinieron en la última parte (del f. 98r en adelante), si es que fueron mas de una. Según la descripción corriente la letra es cuatrocentista, pero no es posible afirmar que no sea de principios del siglo XVI por la evidencia paleográfica" (Whinnom 1961, 163).

La colación abreviada de los cuadernos manuscritos del códice es la siguiente, aunque remito al apéndice para la estructura individual de cada uno de ellos, en la cual -y de ahí su utilidad- se pueden comprobar gráficamente las pérdidas y la solidaridad de los bifolios:

$$
\mathrm{a}^{20} \mathrm{~b}^{16} \mathrm{c}^{16} \mathrm{~d}^{16} \mathrm{e}^{16} \mathrm{f}^{16} \mathrm{~g}^{16} \mathrm{~h}^{16} \mathrm{i}^{16} \mathrm{j}^{16} \mathrm{k}^{16} \mathrm{l}^{16} \mathrm{~m}^{16} \mathrm{n}^{20} \mathrm{o}^{8-1} \mathrm{p}^{8} \mathrm{q}^{16} \mathrm{r}^{8-1} \mathrm{~s}^{8} \mathrm{t}^{8} \mathrm{u}^{8}
$$


Esta estructura codicológica viene confirmada por los reclamos, por las filigranas y por el cordel del cosido, claramente visible en el interior del cuaderno, en el bifolio central. En cualquier caso, he comprobado siempre la unidad física del bifolio a través de instrumental de restauración, que deja entrever la continuidad material del papel.

Todos los cuadernos de la primera sección del cancionero cuentan con reclamos, a excepción, lógicamente, del que cerraba la recopilación inicial: el cuaderno $n .^{8}$ Esto es, de hecho, una evidencia de ello y de que los materiales impresos y los cuadernos finales, que contenían el Repertorio de los tiempos y el Lunario, se añadieron posteriormente, con fines de conservación meramente pragmáticos.

Los fols. 233 y 236 del primer pliego suelto, conocido por Dutton como $99^{*} \mathrm{RN}$, contienen las dos mitades de una filigrana de la mano enguantada con estrella de siete puntas, muy parecida al modelo 175 de Valls i Subirà, datada en 1516, a partir del impreso toledano de Juan Villaquirán que recoge las Décadas de Tito Livio. Como en el caso de este impreso, las filigranas de los cuadernos manuscritos se encuentran en el pliegue de los bifolios, al ser doblados en cuarto, de manera que el cosido dificulta su identificación. Se pueden distinguir dos de ellas: la cruz de san Andrés hasta el bifolio 274-277, que se confecciona ya con otro papel, que trae la filigrana de la mano enguantada con estrella de cinco puntas y base rizada del guante, parecida al número 11.135 de Briquet, aunque en esta sección del cancionero es con estrella de seis puntas. Después de este bifolio, ya siempre será esta la filigrana que encontremos hasta el final del códice. Esto confirma que la copia de las Coplas de la vita Chris$t i$ es anterior a la del Repertorio de los tiempos. Y, si tenemos en cuenta que este último tiene un uso pragmático y cotidiano, y que no tendría sentido la transcripción de años ya pasados, sabemos que la copia de la segunda sección se produjo en 1493, dado que es el primero de los recogidos en el calendario en cuestión. Esta fecha, en cualquier caso, no debe extrapolarse necesariamente para la compilación del cancionero, por su carácter facticio, aunque sí que parece que la copia de sus partes se produjo en una fecha similar y en un mismo

8. Cuaderno $a$ : "eran" (f. 20v); cuaderno $b$ : "el dulçor" (f. 31v) y "minguillo" (f. 35v); cuaderno $c$ : "pues" (f. 51v); cuaderno $d$ : "O quan" (f. 67v); cuaderno $e$ : "no se que mas" (f. 83v); cuaderno $f$ : "mas" (f. 99v); cuaderno $g:$ :son" (f. 115v); cuaderno $b$ : "altos" (f. 130v); cuaderno $i$ : "comjença" (f. 146v); cuaderno $j$ : "la sesta" (f. 162v); cuaderno $k$ : "prosigue" (f. 178v); cuaderno l: "prosigue" (f. 194v); cuaderno m: "prosigue" (f. 210v). Sorprende, sin embargo, la presencia de dos reclamos en el cuaderno $b$. 
contexto. Si tenemos en cuenta que la filigrana más extendida en el códice, la de la cruz de san Andrés, es muy parecida -si no idéntica- al tipo 5.719 de Briquet, la datación de este papel en Francia ya en 1489 o, incluso, en 1487 insiste en estas fechas de copia, ligeramente posteriores, como también lo hace la documentación única de la 11.135 en Palermo en 1487. Aunque es cierto que el Repertorio de los tiempos es un documento externo al cancionero de Mendoza, está transcrito indudablemente en el mismo entorno e, incluso, por el mismo copista, de manera que debió de conservarse junto a él y después llegó a coserse al códice completo, junto a los materiales impresos. Sin embargo, parece evidente que los primeros folios reaprovechan el papel sobrante adquirido ad hoc para la copia del cancionero de Mendoza. Y no tendría razón de ser en sentido contrario, porque el Repertorio de los tiempos se completa con papel más moderno.

\section{LOS DATOS INTERNOS}

En cuanto al listado de obras, Whinnom $(1961,163)$ no incluye como parte del códice los textos impresos que lo cierran, pero da noticia del primer pliego suelto. Zarco (II, 175) sí que nos advierte de que "hay entre las piezas mss. los siguientes impresos incunables de letra gótica” y los cataloga, aunque con numeración romana y previamente al listado en arábiga de las obras manuscritas. Ambos autores se refieren a $99^{*} \mathrm{RN}$ como dos impresos sueltos diferentes (Zarco II, 175; Whinnom 1961, 162-63), ${ }^{9}$ cuya tipografía, de hecho, así lo confirma. ${ }^{10}$ Benigno Fernández $(1904,586)$, sin embargo, se limitaba a hablar de dos pliegos sueltos cosidos a EM6 y no daba referencia del poema Con pena y cuydado continuo guerreo (Martos 2012a). A su vez, Dutton aporta tan solo dieciocho composiciones, pues excluye las dos que identifica bajo el pliego $99^{*} \mathrm{RN}$, al que remite; por otro lado, también elimina el pliego suelto del Pseudo Bernardo (ff. 238r-241v) (BETA manid 3614), mientras que en esta tabla distingo entre la obra de Andrés de Li y la de Bernat de Granollachs como textos diferentes, más allá de que provengan de una misma edición.

Las veinte piezas que contiene el cancionero EM6 son, en definitiva, las siguientes, de las que aporto la foliación, el autor, la transcripción de la rúbri-

\footnotetext{
9. Y así lo reproduce BETA en manid 1238 y 3613.

10. Agradezco a Mercedes Fernández Valladares que me haya acompañado a El Escorial para confirmar mi hipótesis desde el análisis de los tipos, pues otros criterios me sugerían, como desarrollaré en otro trabajo, que Zarco tenía razón y eran dos impresos.
} 
ca, del íncipit y del éxplicit, la referencia a su carácter impreso o manuscrito, el número de identificación de Brian Dutton para los textos en verso y aquellos en prosa que también la tengan y, finalmente y en nota, los principales errores de transcripción de algunos textos:

1. (ff. 1r-97r) Fray Íñigo de Mendoza. Comiença la vida de nuestro redenptor ibesu christo en estillo metrico conpuesta por un frayre menor de obseruancia a pedimiento de doña juana de cartajena. Incipit: [A]clara ${ }^{11}$ sol diuinal I la cerrada niebla escura. Explicit: que si rejalgar allaran I triaca no la boluieran. Deo gracias. Manuscrito. ID 0269. ${ }^{12}$

2. (ff. $98 \mathrm{r}-111 \mathrm{v}$ ) Fray Íñigo de Mendoza. Sermon trobado que bizo fray ynigo de mendoça al muy alto el muy poderoso prinçipe rey y señor el rey don fernando rey de castilla de aragon sobre e yugo y coyundas que su alteza trahe por deujsa. Inc.: Principe muy soberano I nuestro natural señor. Exp.: de tan alta calidad I quanto es mj voluntad. Manuscrito. ID 0270.

3. (ff. 112r-116bis v) Fray Íñigo de Mendoza. Coplas que yzo fray yñigo de mendoça frayre menor doze en vituperio de las malas henbras que no pueden las tales ser dichas mugeres e doze en loor de las buenas mugeres que mucho triunpho de honor merecen. Inc.: En este mundo disforme I do la virtud y bondad. Exp.: diablos en suzio establo I a los onbres bestias atan. ${ }^{13}$ Manuscrito. ID 0271.

4. (ff. $117 \mathrm{r}, 124 \mathrm{v}-145 \mathrm{v}$ ) Fray Íñigo de Mendoza. Coplas conpuestas por fray ynigo de mendoça al muy alto e muy podero $[\text { so }]^{14}$ prinçipe rey e señor el rey don fernando de castilla e de leon e de çeçilia prinçipe de aragon $\tau$ a la muy esclareçida reyna doña ysabel su muy amada muger nuestros naturales señores en que declara commo por el aduenjmjento destos muy altos senores es reparada nuestra castilla. Inc.: Prologo. O diuina caridad I quien limpia nuestras manzillas. Exp.: que el trauajo enbegeçido I nunca se podra cobrar..$^{15}$ Manuscrito. ID 0272.16

11. Se deja el hueco para la iluminación de la capital, que falta.

12. Las Coplas de la vita Christi están copiadas según la pauta de dos estrofas por folio, a excepción de la última, transcrita sola en el fol. 97r. Dutton advierte también que dentro de esta obra se encuentran incorporadas las composiciones con ID 4304 C 0269 y 8106 G 0862.

13. Esta obra se repite en el cancionero, ya que aparece en los fols. $225 \mathrm{r}-231 \mathrm{v}$.

14. La esquina superior del folio está desgastada y falta papel.

15. "Sólo, por equivocación del copista, la primera copla y los cinco primeros versos de la segunda. A continuación siguen los versos de la copla cuarta de La justa de la razón, y sigue el texto de esta última pieza" (Zarco II, 176).

16. Dutton advierte que está "incompleto. Lo que falta se encuentra abajo en $124 \mathrm{v}-145 \mathrm{v}$ ” (I, 67). 
5. (ff. 117r-120v) Fray Íñigo de Mendoza. LLa justa de la razón contra la sensualidad] Acéfalo. Inc.: por lo qual la real vida I segund dixieron los viejos. Exp.: y las santas religiones I y los limpios pensamientos. Manuscrito. ID 2091. ${ }^{17}$

6. (ff. 121r-124r) Fray Íñigo de Mendoza. [Los gozos de Nuestra Señora] Acéfalo. Inc.: O quanta gloria sentiste I quando despues de adorado. Exp.: con tu alma juntamente I se sobio. Manuscrito. ID 0325.18

7. (ff. 124r-v) Fray Ínigo de Mendoza. Coplas hechas por fray ynigo de mendoça en que pone la cena que nuestro señor bizo con sus diçipulos quando inestituyo el santo sacramento del su sagrado cuerpo. Inc.: Inbocaçion. Tu que solo dios meresçes I que te pidamos fabor. Exp.: y tu diujna destreza | adiestra tan çiego frayre. ${ }^{19}$ Manuscrito. ID 2891.

8. (ff. 146r-156v) Fray Íñigo de Mendoza. Dechado que bizo fray ynigo de mendoça al muy esçelente reyna doña ysabel nuestra souerana señora. Inc.: Alta reyna esclareçida I guarnesçida. Exp.: neçios en remar los remos I pueble roma sus estremos. Manuscrito. ID 0273.

9. (ff. 157r-183v) Juan de Mena. Coplas que fizo el famoso juan de mena contra los pecados mortales. Inc.: Canta tu christiana musa I la mas que çevjl batalla. Exp.: que su yra uo perdona I ser perdonado su viçio. Manuscrito. ID 0100.

10. (ff. $183 \mathrm{v}-213 \mathrm{v}$ ) Gómez Manrique. Por fallesçimiento del famoso poeta juan de mena prosigue gomez manrrique aquesta obra por el començada y faze vn breue probemio. Inc.: Pues este negro morir I que a ninguno no perdona. Exp.: ser amados de verdad I a los christianos amad. Manuscrito. ID 0101 a 0100.

11. (ff. 213r-214r) Sancho de Rojas. Pregunta de sancho de rojas a un aragones que entraba sobre mar. Inc.: Como quien sube trepando I por las cuerdas del nauio. Exp.: juizio de tal conpas I dezime señor qual es. ID 0274 .

12. (f. 214r) Anónimo. Respuesta del aragones. Inc.: Vuestro saber cotejando I con el poco saber mio. Exp.: mira amor que gloria das I a quien se bumjlla a tus pies. Manuscrito. ID 0275 R 0274.

17. "Le faltan a esta composición el título, la dedicatoria en prosa a la Reina, las tres primeras coplas de la introducción y los cinco primeros versos de la copla 4. ${ }^{\mathrm{a}}$, y acaba en la 18 , sin tener las demás" (Zarco II, 176).

18. "Empieza en la copla 14 del impreso. Lo restante está completo" (Zarco II, 176).

19. "Sólo contiene la primera copla y los 5 primeros versos de la segunda" (Zarco II, 177). 
13. (ff. 214r-215r) Jorge Manrique. Coplas que fizo don forge sobre que es amor. Inc.: Es amor fuerça tan fuerte I que fuerça toda razon. Exp.: que no puede conportar I el falso cobre dorado. Manuscrito. ID 0276.

14. (ff. 215r-225r) Jorge Manrique. Coplas que fizo don forge manrrique a la muerte del maestre de santiago don rodrigo manrrique su padre. Inc.: Recuerde ell alma dormida I abiue el seso y despierte. Exp.: aquj yaze muerto el onbre I que biuo queda su nonbre. Manuscrito. ID 0277.

15. (ff. 225r-231v) Fray Íñigo de Mendoza. Coplas que fizo fray ynigo de mendoça frayre menor doze en vituperio de las malas henbras que no pueden las tales ser dichas mugeres $E$ doze en loor de las buenas mugeres que mucho triunpho de honor mereçen. Inc.: En este mundo disforme I do la virtud y bondad. Exp.: diablos en suzio establo I a los onbres bestias atan. ${ }^{20}$ Manuscrito. ID 0271.

16. (ff. 232r-236v) Ambrosio de Montesino. Siguen se vnas Coplas muy deuotas fechas a reuerencia del nacimiento de nuestro señor jhesu cristo $\tau$ cantan se al son dela zorrilla conel gallo. Inc.: El infante y el pecado I mal han barajado. Exp. (fin del texto conservado): como ruy señor en prado I mal han barajado. Impreso. $4^{\circ} .-\mathrm{a}^{8}\left[\mathrm{i}^{\mathrm{iiij}+4}\right] .-8$ h. (ejemp. mútilo de aij, a7 y a8). ID 0278 т 0279.

17. (ff. 237r-v) Anónimo. Estas coplas son de arte mayor y las medias coplas estan todas en razon y por consonantes y juntas media y media es vna de arte mayor y tambien puestas en razon y por consonantes. Inc.: Con pena y con cuydado continuo guerreo I sin consolacion con poca esperança. Exp.: Guis sin par es el vuestro nombre I añadiendo el tercero hombre. ${ }^{21}$ Impreso. $4^{\circ} .-[]^{22} .-\dot{\chi}^{2}$ h.? (solo conservada una hoja). ID 0280.

18. (ff. 238r-241v) Pseudo Bernardo, Bernardus Claravallensis. Comiença la epistola de san Bernardo a reimundo cauallero su sobrino de la manera y forma que se deuen regir la bazienda E la casa Dize san bernardo al Reimundo. Inc.: Uirtuoso $\tau$ generoso cauallero. Exp.: su mala vejes. Impreso. $4^{\circ}$.- [ ] $]^{4}$.- 4 h. BETA manid 3614.

19. (ff. 242r-273v) Andrés de Li. Reportorio de los tienpos ordenado por addiciones en el lunario: ffecho por andres de li cibdadano de çaragoça dirigido al muy magnifico $\tau$ muy virtuoso bidalgo y señor don pedro torrero II

20. Esta obra se repite en el cancionero, ya que aparece en los fols. $112^{\mathrm{a}}-116 \mathrm{bis}$. "Estas Coplas son más perfectas que las del número 3" (Zarco II, 183).

21. Hay dos folios en blanco después del 237, que no se cuentan en la foliación de EM6, aunque en el recto del primero de ellos sí que se indica 237 bis $v$. 
Comiença el reportorio de los tienpos. [En] aquel tienpo feroce y muy rustico. Inc.: pprologo. [C]onoscida 22 cosa es muy magnifico. Exp.: si la luna esta. ${ }^{23}$ Manuscrito. ID 0281.

20. (ff. 274r-303v) Bernat de Granollachs. Inc.: [D] $e^{24}$ la muy noble arte $\tau$ sciencia de astrologia. Exp.: sera letra dominicale II Señor muy virtuoso buuiendo arriba complido con su merced en las cosas que dan algun conplimiento ala obra presente lo qual no solo era prouechoso mas muy necessario no hera razon que en tan noble y esclarescida ciudad se imprimiese cosa que en otro lugar se hallase viciosa e por ende por obra y studio del honrrado fadrique aleman de vasilea ha seydo otra vez agora nueuamente con diligencia corregido y emendado el lunario porque sin recelo de topar con algun ingenio maliuolo vaya desenvueltamente por todo e porque como reza valerio no bay ninguna bumildad tan pequeña que no sea algun poquito tocada de dulcedunbre de gloria lo bizo el inprimir a sus costas en aquesta real y magnifica cibdad de burgos fue acauada a xxi del mes de mayo del ano mil.ccc.xciii. Manuscrito.

\section{Las Coplas de la Vita Christi y la edición de Centenera de 1483}

Sorprende que Whinnom (1961) no cite la descripción de Fernández y que, sin embargo, presente tantas similitudes en cuanto a los datos físicos y a las conclusiones de su trabajo sobre la dependencia parcial de EM6 respecto de la edición de Centenera, c. 1483, a excepción de las Coplas de la vita Christi, que se interpretan como un estadio del texto inmediatamente anterior al de las ediciones:

Todas las piezas aquí indicadas, si se exceptúa el Vita christi, guardan casi perfecta conformidad con el texto de la edición zamorana de hacia 1483. En cambio, las variantes que ofrece el texto manuscrito de aquel poema son tan considerables, que puede muy bien tenérsele como representante de una primera redacción en la que más tarde fueron corregidas algunas estrofas y añadidas otras. Como muestra, copiamos á continuación las ocho primeras coplas del ms., anotando al margen las variantes de la edición zamorana, que son las mismas que ofrece otra edición incunable,

22. La capital está sin miniar, aunque sí que se marca la letra que debe ser iluminada.

23. "Sin acabar. Hay señales de una hoja arrancada" (Zarco II, 183).

24. La capital está sin miniar, aunque sí que se marca la letra que debe ser iluminada. 
sin lugar ni año, pero hecha en Zaragoza por el año 1480. (Fernández 1904, 589)

Fernández fue, por tanto, el primero en determinar la singularidad de esta copia manuscrita de las Coplas de la vita Christi, que no son una transcripción del cancionero impreso $83^{*} \mathrm{IM}$, como sí ocurre con las composiciones que la siguen. Si Whinnom parte, indudablemente, de las conclusiones de Fernández, Severin lo hace de las de Whinnom, para desarrollarlas muy sólidamente, sin citar, por esas ironías de la investigación, el origen de tal hipótesis por lo que respecta a EM6. En "una historia de revisiones de autor, tanto para la circulación en manuscrito en la corte de los Reyes Católicos, como para la imprenta destinada a un público más masivo y popular" (Severin 2017, 291), Severin establece cuatro recensiones de las Coplas de la vita Christi (ver Severin 2007), a la tercera de las cuales pertenecería la de este cancionero manuscrito. Amplía, así, la primera hipótesis de Whinnom (1961, 1962 y 1977) e, incluso, la suya misma (Severin 2004). Esta tercera recensión estaría formada, en exclusiva, por los cancioneros SA4a y EM6, ${ }^{25}$ pero entre ellos hay diferencias:

SA4a [...] es la versión más larga del manuscrito revisado, que circulaba en la corte al final del siglo XV. Incorpora partes reescritas por extenso, con la mayoría del comentario político expurgado. Sin embargo, no fue la versión utilizada para la imprenta [...]. A pesar de la mucha reescritura, contiene tantas estrofas como HH1. Sus dos últimas estrofas, mal consideradas únicas, también figuran como las dos primeras estrofas de ID 7815, f. 119r; véase también SA9.

EM6, una versión muy estrechamente relacionada con SA4a, pero que carece de las últimas dos estrofas reescritas de SA4a. Sin embargo, contiene tres estrofas de la tradición temprana que no figuran en SA4a, y dos de ellas aparecen en la tradición impresa. Escorial K-III-7, ff. 1r-97r. (Seve$\operatorname{rin} 2017,292)^{26}$

25. Si bien es cierto que de este estadio textual de SA4a "hay otra versión de la misma en Salamanca 2139, ff. 71r-122r" (Severin 2017, 292), por lo que, aunque Dutton no haya catalogado este otro testimonio, habría que hablar de tres manuscritos diferentes en esta recensión, si bien dos de ellos coincidirían en una versión.

26. He cotejado ambos cancioneros manuscritos de manera sistemática y, además de las rúbricas, cuya desaparición, aglutinación a la estrofa anterior o reordenación caracteriza puntualmente SA4 frente a EM6, también encuentro las siguientes discrepancias: la copla 327 de SA4 no aparece en EM6, mientras que las coplas 366-369 de SA4 aparecen en EM6 como las 371-374 y las 374-377 de SA4 lo hacen en EM6 como 383-386. Ver Severin 2017. 
A pesar de no corresponder exactamente a la versión impresa, tales diferencias reivindican la textualidad de EM6 como la más cercana a esta ${ }^{27} \mathrm{y}$, por tanto, debe destacarse respecto de SA4a, aunque comparto con Severin que ambas pertenezcan a una misma recensión. Un dato como este implica una relevancia ecdótica del testimonio de EM6 para la textualidad de las Coplas de la vita Chris$t i$, que había sido menostenida, sin lugar a dudas, por influencia o contaminación de los materiales que le siguen, que son copia del impreso $83^{*} \mathrm{IM}$. Para ellos, este es un codex descriptus, sin funcionalidad ecdótica, pero en cuanto a las $\mathrm{Co}^{-}$ plas de la vita Christi, el testimonio de EM6 es clave para entender su evolución textual hacia la imprenta y, como versión de autor, para avalar algunas soluciones textuales impresas y descartar, así, posibles intervenciones al respecto ajenas a fray Íñigo que se hubiesen producido durante el proceso editorial.

Fernández nos advierte, por otro lado, de la dependencia textual de las siguientes obras respecto del cancionero impreso $83^{*} \mathrm{IM}$, una hipótesis que he podido confirmar y ratificar a partir de la collatio codicum completa entre las versiones de este impreso y del cancionero manuscrito EM6 por lo que respecta a la Coplas a la muerte de su padre de Jorge Manrique y a las Coplas en vituperio de las malas hembras de fray Íñigo de Mendoza. He recurrido a ello no solo como procedimiento ecdótico habitual, sino porque la primera fase de este, la correspondiente a la collatio externa, me aportaba datos de una cierta distorsión: ${ }^{28}$ los errores de transmisión de la composición ID 0272, la ausencia de ID 2900 p 2091 y la acefalia de ID 2900, ${ }^{29}$ el cierto desorden de la copia respecto a la fuente impresa o la duplicación de las Coplas en vituperio de las malas hembras, que se copian, primero, en su secuencia correspondiente y, después, al final del cancionero, justo a continuación de las Coplas a la muerte de su padre, que estaban desordenadas y se habían desplazado a esa posición. Precisamente por esto y porque las Coplas manriqueñas también se habían transmitido como pliego suelto, seleccioné ambos textos para la collatio codicum, por si, en este caso, se trataba de antígrafos diferentes a $83^{*} \mathrm{IM}$, cuyo resultado, sin embargo, es la confirmación de la hipótesis de Fernández: suponen un codex descriptus, aunque parcial, una copia manuscrita de un impreso (Martos 2011).

27. Entre SA 4 y $83^{*} \mathrm{IM}$ advierto que entre las coplas 124 y 125 de SA $4,83^{*} \mathrm{IM}$ añade dos estrofas, mientras que entre las coplas 326-327 de $83^{*} \mathrm{IM}$ habría una estrofa en SA4, que no se recoge en el impreso. Finalmente, en SA4 faltan las estrofas $128-130,142,218-224,269$ y $276-279$ de $83^{\star} \mathrm{IM}$.

28. Anotados, asimismo, en la tabla de obras de la estructura interna que ofrezco en este trabajo.

29. Una circunstancia que no coincide con un cambio de cuaderno, que se pudiera justificar por una pérdida en este manuscrito -aunque quizás sí de su antígrafo-, como se puede comprobar en la estructura codicológica del apéndice. 
Podríamos plantearnos que, si buena parte de los materiales de EM6 son una copia manuscrita del cancionero impreso $83^{*} \mathrm{IM}$, ¿por qué no se copian también de él las Coplas de la vita Christi? La razón es evidente: porque el procedimiento es, en realidad, inverso y complementario. Previamente, se dispone de un antígrafo de esta extensa obra de fray Íñigo que debía de ser un testimonio de autor o muy cercano a él y a la corte de los Reyes Católicos, contexto en el cual lo copia, muy probablemente, el poseedor de los materiales que dieron lugar a EM6, que también debía de pertenecer a ella, como veremos. Era una versión o recensión muy cercana a la imprenta, que se decide acompañar de otros textos que aparecían en el cancionero $83^{*} \mathrm{IM}$, un impreso que, lógicamente, no era de propiedad del copista y, de ahí, su transcripción, un incunable que, sin lugar a dudas, se debió de convertir en el referente canónico para su obra en aquel entonces, como pasó con muchos otros poetas al llevarse a las prensas. Solo hay que ver para ello la aparición de este entre los libros de Isabel la Católica (Ruiz 477).

\section{LOS IMPRESOS DE BURGOS}

El proceso de transcripción del Repertorio de los tiempos debía de responder a unas causas muy parecidas a las del cancionero $83^{*} \mathrm{IM}$, al no poseeerlo el copista y más allá de tratarse de un impreso de cierto interés pragmático, pues, si solo hubiese sido este, no habría incorporado toda la sección de Andrés de Li y se habría limitado a las tablas de Bernat de Granollachs. La única copia manuscrita del Repertorio de los tiempos es, de hecho, esta que cierra el cancionero EM6, con la suerte de que se transcribe el colofón:

Señor muy virtuoso huuiendo arriba complido con su merced en las cosas que dan algun conplimiento a la obra presente lo qual no solo era prouechoso mas muy necessario no hera razon que en tan noble y esclarescida ciudad se imprimiese cosa que en otro lugar se hallase viciosa e por ende por obra y studio del honrrado fadrique aleman de vasilea ha seydo otra vez agora nueuamente con diligencia corregido y emendado el lunario porque sin recelo de topar con algun ingenio maliuolo vaya desenvueltamente por todo e porque como reza valerio no hay ninguna humildad tan pequeña que no sea algun poquito tocada de dulcedunbre de gloria lo hizo el inprimir a sus costas en aquesta real y magnifica cibdad de burgos fue acauada a xxi del mes de mayo del año mil.cccc.xciii. ${ }^{30}$

30. La transcripción es mía. Para la tradición editorial completa de esta obra en los siglos XV y XVI, véase Haro Cortés en prensa. 
Precisamente por ello, no se explica que Julián Zarco identifique esta copia manuscrita con una edición diferente a la de Fadrique de Basilea: "Este ms. corresponde a la edición de Burgos, 1495, por Juan de Burgos. $4^{\circ}$ de 74 hs.” (II, 183). No tiene sentido tampoco que Benigno Fernández interprete que de esta "nota final se desprende que sirvió de original para la edición hecha en Burgos en 1493 por el honrado Fadrique alemán de Basilea" y no que "la copia se hizo sobre el impreso, lo cual no es creíble" (1904, 587), como corrige ya Haebler, a pesar de recibir esta noticia de aquel: "Con esto se prueba que el manuscrito es copia de un impreso hoy perdido. Debo la noticia de este hecho muy curioso á la fineza del R. P. Fr. Benigno Fernández, dignisimo bibliotecario Escurialense" (Haebler 360, n. $\left.{ }^{\circ} 201 \mathrm{bis}\right)$.

Este testimonio manuscrito proviene, por tanto, de un impreso salido de las prensas burgalesas de Fadrique de Basilea el 21 de mayo de 1493 (GW M18075), del que se han conservado dos ejemplares: uno en la Biblioteca Nacional de España (INC-547) y otro en la Hispanic Society of America. Del primero, el de la BNE, sin embargo, solo contamos con la sección de Granollachs, precisamente -aquí sí- por el carácter pragmático de esta y, con mucha probabilidad, por una venta exenta, pero complementaria, a la manera de otros impresos incunables y post-incunables (Martos 2012b), por lo que es muy probable que no se trate de un ejemplar mútilo, sensu stricto, sino de un impreso adquirido de manera independiente. De hecho, a este modelo de venta fascicular apuntaría que no contase con signatura de cuaderno la sección de Granollachs, localizada al final de la obra conjunta. Además, dado que el enriquecimiento de la primera sección con grabados encarecería mucho el producto, era lógico que se previese una venta exenta de la sección más funcional de él, como estrategia comercial de un producto de amplio uso. Frente a este, el ejemplar de la Hispanic Society sí que cuenta con la sección de Andrés de Li, pero se han perdido algunos folios de su parte final, correspondiente a los meses; en concreto, faltan enero y agosto, y parcialmente, febrero. Esto corresponde a la pérdida del bifolio externo del cuaderno ( $\mathrm{d} 1 \mathrm{y} \mathrm{d} 8$ ) y a la rotura $\mathrm{de} \mathrm{d} 2$, del que se ha conservado solo un fragmento, probablemente por una pérdida previa a la encuadernación y posterior a la de las otras dos hojas. A estas habría que sumar otra mutilación, que da lugar a la ausencia de dos hojas del cuaderno siguiente (e6 y e7), si bien se conserva e8, cuya caja de escritura solo se aprovecha parcialmente y en el recto, para rematar la obra de Li. Para estas pérdidas, la copia manuscrita de este impreso en EM6 es su único testimonio y de ahí su interés, porque, a pesar de las reservas ecdóticas, nos permite completar un estadio incipiente del texto para el estudio de las edi- 
ciones del Repertorio de los tiempos de Andrés de Li. Esta es una muestra más, por tanto, del valor de las copias manuscritas de impresos.

Si este incunable transcrito proviene de Burgos y, en concreto, del taller de Fadrique de Basilea, no debe pasarnos desapercibido que a él pertenecían también los otros tres impresos incorporados directamente a este códice, todos ellos ejemplares únicos y en dos de los casos, desgraciadamente, mútilos:

a) el de Ambrosio de Montesino -aunque sin atribuir en este impreso-, Siguen se vnas Coplas muy deuotas fechas a reuerencia del nacimiento de nuestro señor jhesu cristo $\tau$ cantan se al son dela zorrilla conel gallo (ID 0278 T 0279);

b) el que contuvo la composición Estas coplas son de arte mayor y las medias coplas estan todas en razon y por consonantes y juntas media y media es vna de arte mayor y tambien puestas en razon y por consonantes (ID 0280);

c) y el del Pseudo-Bernardo, Comiença la epistola de san Bernardo a reimundo cauallero su sobrino de la manera y forma que se deuen regir la bazienda E la casa Dize san bernardo al Reimundo.

Aunque todos ellos son sine notis, tanto el Gesamtkatalog der Wiegendrucke como el Incunabula Short Title Catalogue datan el primero c. 1498 (GW 07466 e ISTC ic00875500); para el segundo, no se propone fecha en GW $0746610 \mathrm{~N}$ y ni siquiera se recoge en ISTC; y el tercero presenta una mayor discrepancia entre ambos repertorios $c .1495$ (ISTC ib00382900) o $c$. 1498-1499 (GW 03995). Los dos primeros incunables poéticos, en cualquier caso, comparten tipografía, que se corresponde a 8:110G, con M88, documentada entre 1493 y 1500 , según el Typenrepertorium der Wiegendrucke (TW-ID ma03790), si bien traspasa el periodo incunable y, para ello, hay que recurrir al espléndido trabajo de Mercedes Fernández Valladares sobre la imprenta en Burgos. ${ }^{31}$ Son datables, por tanto, en una horquilla temporal entre 1495 y 1499, aunque 1498 es la compartida por todos ellos, según estas propuestas.

Tales coincidencias en taller y fechas de los impresos parecen apuntar a una misma procedencia e, incluso, compra de los materiales, a la manera de las realizadas por Isabel la Católica para enviar a sus hijas María y Catalina, alejadas de la corte por sus matrimonios, aunque en este caso salidos de un taller diferente: "A mi juicio, los ejemplares de estos libros de molde habrían sido adquiridos ex professo. Se da la circunstancia de que muchos de ellos fueron

31. Que, si bien no recoge estas entradas concretas, al tratarse de incunables, sí que hace un estudio tipográfico completo de los talleres de esta ciudad. 
editados por Meinardo Ungut y Estanislao Polono, tipógrafos que gozaron de la protección real" (Ruiz 122). Si bien estos regalos de la reina a ambas hijas están documentados, no ocurre así con los de la primogénita, Isabel, pero sí que tenemos constancia de un "cofre forrado de cuero castaño" con libros suyos, cuyo contenido correspondería al tipo de obras que la reina Católica envió a sus otras hijas cuando estuvieron en las mismas circunstancias que esta, que, aunque muy brevemente, fue reina consorte de Portugal: "A todos los efectos, la partida de las dos infantas (H1-3) coincide con las tendencias observables en la de su hermana doña Isabel (F), en lo que respecta a contenidos, lengua y forma de producción de los ejemplares" (Ruiz 122).

Compras conjuntas de estas características, lógicamente, estaban a la orden del día y no tendríamos que relacionarlas necesariamente con la infanta Isabel y su madre, la reina Católica, más aún porque en tales inventarios no se recogen estas obras, ${ }^{32}$ aunque, al menos en el caso del primer y del tercer pliego, sí que se trataba de literatura religiosa espiritual y/o de formación cristiana y tuvieron o pudieron haber tenido cabida en esos regalos de la monarca a sus hijas. La datación de estos impresos, además y en cualquier caso, coincidiría con el periodo entre la boda de la infanta Isabel con Manuel I de Portugal el 13 de septiembre de 1497 y su muerte el 23 de agosto de $1498 .^{33}$

\section{Martín de Mendieta y los Reyes Católicos, EN CONClusión}

Quizás habría que interpretar estos datos, aparentemente peregrinos, como meras casualidades, si no fuera porque en las hojas de guarda de uno de estos impresos incunables encontramos el siguiente exlibris: "Este libro es de Martín de Mendieta, qui'n se lo urtare en la orca lo [¿...?]” (f. 237bis v). ${ }^{34}$

32. Entre los libros de la reina catalogados por Elisa Ruiz, hay "un quaderno de papel, de marca mediana, escripto de molde, en rromançe, que comiença: «El libro primero que declara del nasçimiento de Nuestro Señor»" (B1 18d), del que, a pesar de ser un pliego y dado que el íncipit es diferente, advierte que "no creo que pueda tratarse de las Coplas muy devotas fechas a reverencia del nacimiento de Nuestro Señor Fhesuchristo, atribuidas a fray Ambrosio Montesino, Burgos: Fadrique Biel de Basilea, ca. 1498, 4" (466).

33. Partió para su boda, precisamente, por su interés para el comercio del libro, desde Medina del Campo.

34. Junto a este y cancelado en parte, se puede ver escrito "[...]rin de Ugalde" (f. 237bis v), con el principio del nombre cancelado con tinta, que no he podido documentar, porque dudo mucho de que se trate del Martín de Ugalde que aparece en el Libro del Limosnero de la Reina, en la entrada 359: "En Córdoua dí por mandado de Su Alteza, díxomelo Fernand Aluarez, a Martín de Ugalde, quinientos mrs. e Juanchu de Guernica ochoçientos, que iua medio çiego. Estos son los que prendieron porque se boluieron de la guerra" (Benito 99). 
Documentamos este personaje por primera vez en 1501 al servicio de Isabel la Católica, perteneciente a la casa de la reina, gracias al Libro de asientos de los gastos de la reina del Archivo de Simancas (Escribanía Mayor de Rentas, Casa Real, leg. 2., núm. 1), asientos que parecen comenzar en 1497 (Torre 7). Se le documenta como hombre de cámara y, por lo tanto, cercano a la monarca, pero sin especificar un cargo concreto: $:^{35}$

Fol. [119-3].- Reyna. Onbre de Camara. Año de 1501. Martin de Mendieta, onbre de Camara que fue de la reina e prinçesa e del prinçipe don Miguel. Asento, en Granada, a 20-II-1501; tyene de su Altesa por onbre de Camara 10.000 mrs. cada año, para que le sean librados desde este año en adelante, segund en vn alvala de su Altesa, que llevo sobrescripta, se contyene [librado hasta 1503]. (Torre 61)

Hasta el año de 1503, al menos, se le libró este sueldo, aunque podríamos no tener datos del año siguiente por la muerte de la reina Isabel, que acaeció el 26 de noviembre de 1504; sin embargo, aunque lo volvemos a documentar en 1505, no debió de seguir al servicio real, porque el 5 de marzo de ese año ya había marchado a Flandes. No solo se advierte que fue hombre de Cámara de la monarca, sino también de la princesa y del príncipe Miguel, heredero de Castilla entre 1499 y 1500, el hijo de Manuel I de Portugal y de la primogénita de los Reyes Católicos; de ahí que fuese Isabel a quien, sin duda, se refería el apunte, dado que se la nombró princesa de Asturias, junto a su esposo, hasta su muerte y tras el fallecimiento del príncipe Juan. Esto retrotraería los servicios reales de Martín de Mendieta, por tanto, a los últimos años del siglo XV, al menos. Y así debió de ser, sin lugar a dudas, porque se le documenta en los años siguientes a 1498 y en 1505 en relación con las posesiones de la princesa Isabel.

La reina Católica previó que, tras su muerte, se liquidasen las deudas mediante venta en almoneda de lo que se considerase necesario, para lo que se concentraron sus pertenencias en la ciudad de Toro, a fin de que Juan de Velázquez, encargado de ejecutar el testamento, procediese a ello. Así, "las personas que tenían efectos a su cargo hubieron de proceder a su data. La tramitación del proceso generó una documentación de carácter contable” (Ruiz 40), entre la que se encuentra el testimonio de la recepción por parte de María de Velasco -la esposa de Juan de Velázquez y en nombre de él- de unos libros que

35. "Son muy numerosos los que figuran como «onbre de Camara»o «moço de Camara». A algunos se les adiciona cargo especial” (Torre 10). 
Martín de Mendieta había entregado previamente al camarero Sancho de Paredes, fechado en Arévalo el 11 de junio de 1505 (AGS, CMC, 1. ' ép., leg. 192, pl. 68ar-69ar) (Ruiz 328-30, doc. 20).

Se trata de un cofre de libros de la princesa Isabel, en poder de Mendieta desde el fallecimiento de la camarera madona Marque, que lo tenía a su cargo, un traspaso del que tenemos constancia en un documento sin datar (AGS, CMC, 1. a ép., leg. 192, pl. 70ar-br) (Ruiz 326-28, doc. 19), que sería no solo anterior al 11 de junio de 1505, sino, incluso, al 5 de marzo de este mismo año, si tenemos en cuenta que en esa fecha se inventariaron "otras arcas de idéntica procedencia, de las cuales el oficial encargado, es decir, Mendieta, al partir para Flandes, «dexó las llaves de todo ello a Su Altesa». En ellas aparecieron, entre otras cosas, catorce cuadernos impresos que contenían el Confesional del Tostado y dos Devocionarios" (AGS, CMC, 1. áp., leg. 192, f. 55v) (Ruiz 50). Por tanto, Mendieta no se encontraba en Castilla ya entonces, ni lo estaba el 11 de junio de 1505 , pues en aquel documento la transacción era, en realidad, entre María de Velasco y Sancho de Paredes. Por otro lado, si bien la fecha de la muerte de la princesa, el 23 de agosto de 1498, sería un terminus post quem para este documento, también es cierto que debió de ser posterior, pues había quedado en posesión de madona Marque hasta la muerte de esta -y no la de la princesa, como se ha querido interpretar recientemente- ${ }^{36}$

En definitiva, los materiales que forman parte del cancionero EM6 provienen del entorno más inmediato de los Reyes Católicos. Las peculiaridades textuales de las Coplas de la vita Christi parecen apuntar a un antígrafo muy cercano a fray Íñigo y previo a la versión impresa, que habría corrido entre la corte o, incluso, que habría formado parte de los libros de la reina y/o de las infantas. Ni hay documento ni creo que lo hubiera jamás respecto del proceso de copia de este antígrafo ni del correspondiente al incunable de Centenera de 1483, pero este cancionero impreso, como canon poético de fray Íñigo, estuvo entre los libros de la reina y, de hecho, fue uno de los regalos a su hija Catalina, cuando ya era princesa de Gales, como se documenta en el cargo de libros fechado el 30 de mayo de 1501 en Granada, en su ítem número 13 (AGS, CMC, 1. ép.,

36. Ruth Martínez Alcorlo parece interpretar en "Lo que está en poder de Mendieta del cargo de madona Marque, que se le entregó en Toledo después de su muerte" que el deceso es el de Isabel, a partir de lo cual data erróneamente el documento: "La datación no está expresa pero se fecha «en Toledo después de su muerte», por lo que puede corresponderse con el otoño de 1498" (697, n. 8). Y eso a pesar de que Elisa Ruiz es explícita en su interpretación: "Cuando falleció la camarera, fueron traspasados a Martín de Mendieta" (46). 
leg. 156, pls. 227-231) (Ruiz 280-83, doc. 7; ver también 477). En eso mismo incide y confirma fehacientemente el hecho de que algunos de estos materiales pertenecieron -sin duda, porque lo documenta un exlibris- a Martín de Mendieta, hombre de cámara de la reina Isabel, de su primogénita y de su nieto, el principe Miguel. Cercano y de servicio directo, por tanto, a estas tres figuras y, en especial, a la princesa Isabel, Mendieta acabó custodiando "una arca de cuero castaño" que perteneció a esta, así como "otras arcas de idéntica procedencia", un detalle este último que ha pasado muy desapercibido.

Todos los materiales del cancionero EM6 debieron de pertenecer a Martín de Mendieta e, incluso, es muy probable que él mismo los copiase, ante su acceso a libros manuscritos e impresos que habían pertenecido a la reina y a la princesa. Esto explicaría, además, su encuadernación conjunta, para proteger y conservar los tres pliegos sueltos, algunos muy deteriorados. Precisamente, los impresos poéticos son los más dañados, un rasgo de materialidad de los ejemplares que podría ser una huella de un uso mucho más frecuente que el del otro impreso; no en vano, de hecho, se encuadernan junto a un cancionero manuscrito y solo las dos últimas secciones se dejan a la prosa, al breve pliego suelto del Pseudo-Bernardo y a la copia manuscrita de otro incunable, el Repertorio de los tiempos salido de las prensas de Fadrique de Basilea en Burgos, como los tres impresos que le preceden en el códice, lo que debe de estar lejos de ser una casualidad.

\section{OBRAS CITADAS}

An Electronic Corpus of 15th Century Castilian Cancionero Manuscripts. 12 de mayo de 2019. <http://cancionerovirtual.liv.ac.uk/main-page.htm>.

Benito Ruano, Eloy, ed. El libro del Limosnero de Isabel la Católica. Madrid: Real Academia de la Historia, 2004.

BETA: Biblioteca Española de Textos Antiguos. Dir. Charles B. Faulhaber. The Bancroft Library. Berkeley: University of California, 1997. 12 de mayo de 2019. <http://vm136.lib.berkeley.edu/BANC/philobiblon/beta_en.html>. Briquet, Carles M. Les Filigranes. 2. ${ }^{\text {a }}$ ed. 4 vols. Hildesheim/Zürich/New York: Georg Olms, 1984.

Dutton, Brian. El cancionero del siglo XV (c. 1360-1520). 7 vols. Salamanca: Universidad de Salamanca, 1990-1991.

Fernández, Benigno. "Incunables españoles de la Biblioteca escurialense". La Ciudad de Dios 63 (1904): 586-99.

Fernández, Benigno. "Incunables españoles de la Biblioteca del Escorial”. La Ciudad de Dios 86 (1911): 55-70. 
Fernández Valladares, Mercedes. La imprenta en Burgos (1501-1600). 2 vols. Madrid: Arco Libros, 2005.

GW: Gesamtkatalog der Wiegendrucke. Leipzig: Hiersemann. 12 de mayo de 2019. <http://www.gesamtkatalogderwiegendrucke.de/>.

Haebler, Konrad. Bibliografía ibérica del siglo XV. La Haya: Martinus Nijhoff/Leipzig: Karl W. Hiersemann, 1903.

Haro Cortés, Marta. "Una nueva edición del Repertorio de los tiempos de Andrés de Li: Burgos, Juan de Junta, 1533”. Boletín de la Real Academia Española, en prensa.

ISTC: Incunabula Short Title Catalogue. London: British Library. 12 de mayo de 2019. <http://www.bl.uk/catalogues/istc>.

Martínez Alcorlo, Ruth. “«En una arca de cuero castaño»: los libros de Isabel, primogénita de los Reyes Católicos". "En Doiro antr'o Porto e Gaia”: estudos de literatura medieval ibérica. Eds. José Carlos Ribeiro Miranda y Rafaela da Câmara Silva. Porto: Estratégias Criativas, 2017. 695-710.

Martos, Josep Lluís. Del impreso al manuscrito en los cancioneros. Alcalá de Henares: Centro de Estudios Cervantinos, 2011.

Martos, Josep Lluís. "Un impreso poético en el cancionero manuscrito EM6: el pliego suelto 99*RN y el Cancionero General". Letras 65-66 (2012a): 243-54.

Martos, Josep Lluís. "Sobre l'Spill de la vida religiosa i la impremta". Zeitschrift für Katalanistik 25 (2012b): 229-58.

Rodríguez-Puértolas, Julio, ed. Fray Íñigo de Mendoza y sus Coplas de Vita Christi. Madrid: Gredos, 1968.

Ruiz García, Elisa. Los libros de Isabel la Católica: arqueología de un patrimonio escrito. Salamanca: Instituto de Historia del Libro y de la Lectura, 2004.

Severin, Dorothy. "Las tres versiones de la Vita Christi de fray Íñigo de Mendoza". Del manuscrito a la imprenta en la época de Isabel la Católica. Kassel: Reichenberger, 2004. 47-67.

Severin, Dorothy. "The Four Recensions of fray Íñigo de Mendoza's Vita Cbris$t i$ with Some Unpublished Stanzas". From the Cancioneiro da Vaticana to the Cancionero general: Studies in Honour of Jane Whetnall. Eds. Alan Deyermond y Barry Taylor. Londres: Queen Mary University of London, 2007: 225-34. Severin, Dorothy. "Fray Íñigo de Mendoza del manuscrito a la imprenta: ¿un caso de autocensura?". Variación y testimonio único: la reescritura de la poesía. Alicante: Universidad de Alicante, 2017: 291-303.

Torre, Antonio de la. La casa de Isabel la Católica. Madrid: CSIC, 1954.

Valls i Subirà, Oriol. Paper and Watermarks in Catalonia. Amsterdam: The Paper Publications Society, 1970. 
Whinnom, Keith. "Ms. Escurialense K-III-7: el llamado Cancionero de Fray Íñgo de Mendoza". Filología 7 (1961): 161-72.

Whinnom, Keith. "The Printed Editions and Text of the Works of Fray Íñigo de Mendoza". Bulletin of Hispanic Studies 39 (1962): 137-52.

Whinnom, Keith. "Fray Íñigo de Mendoza, Fra Jacobo Maza, and the Affiliation of Some Early Mss of the Vita Christi". Annali di Ca' Foscari 16 (1977): 129-39.

Zarco Cuevas, Julián. Catálogo de los manuscritos castellanos de la Real Biblioteca de El Escorial. 3 vols. Madrid: 1924-1929.

\section{APÉNDICE}

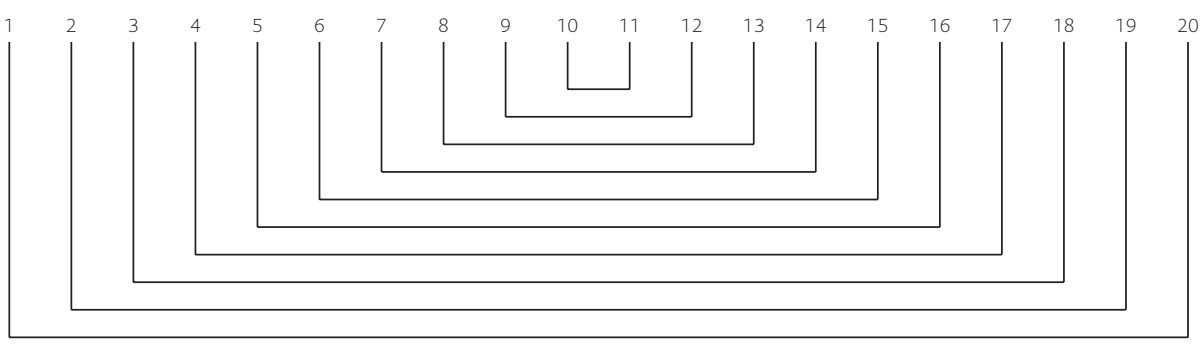

Cuaderno a

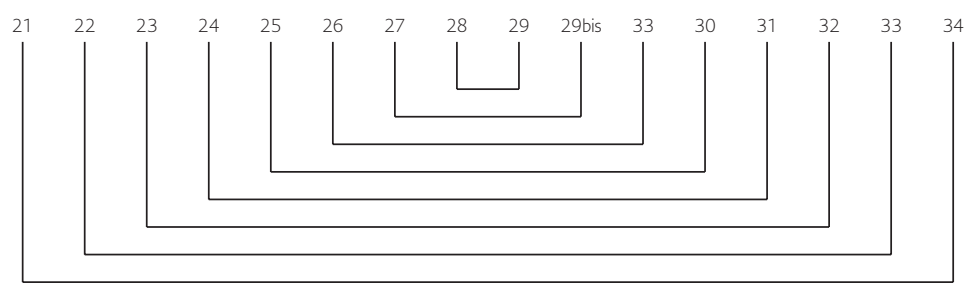

Cuaderno b

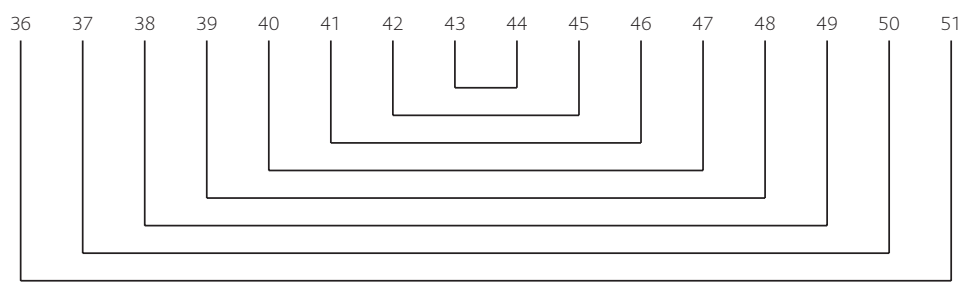

Cuaderno c 
MARTOS. MANUSCRITOS E INCUNABLES EN TORNO A LOS REYES CATÓLICOS: CANCIONERO EM6

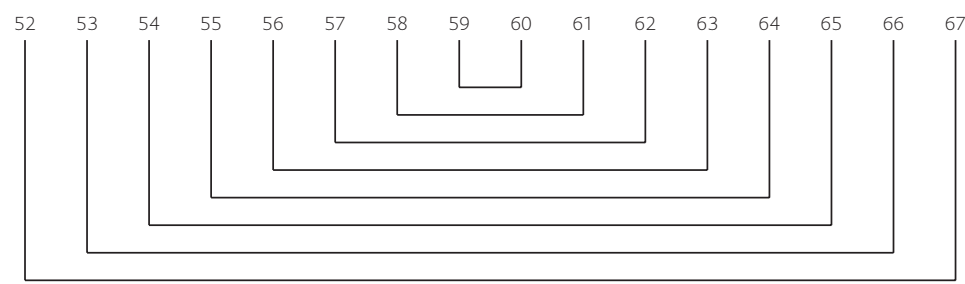

Cuaderno d

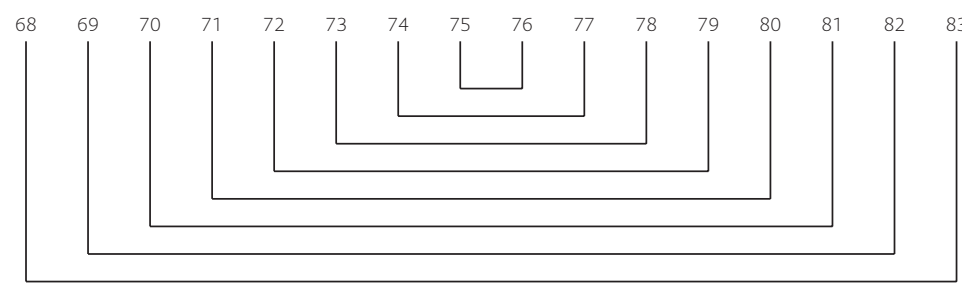

Cuaderno e

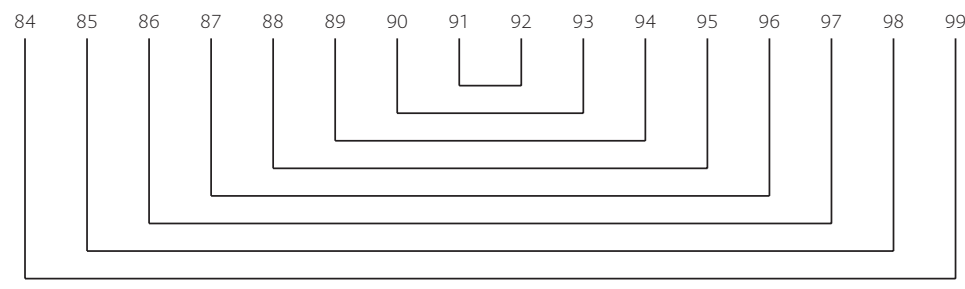

Cuaderno $f$

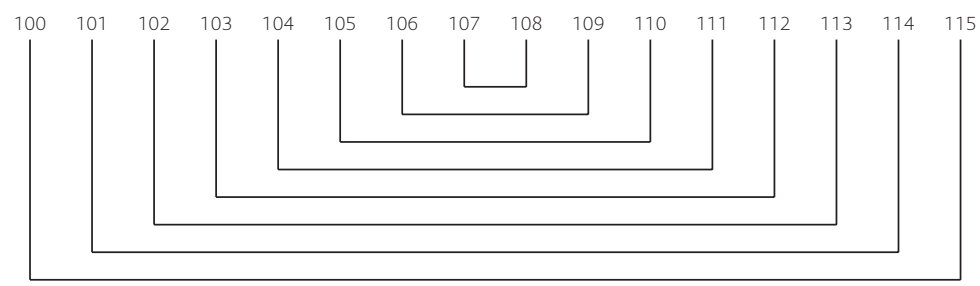

Cuaderno g 


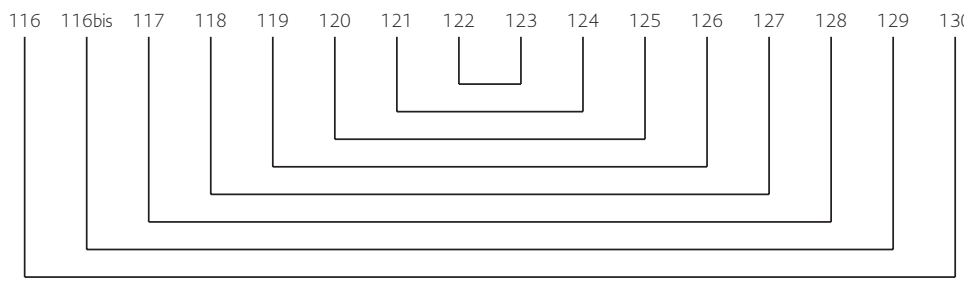

Cuaderno h
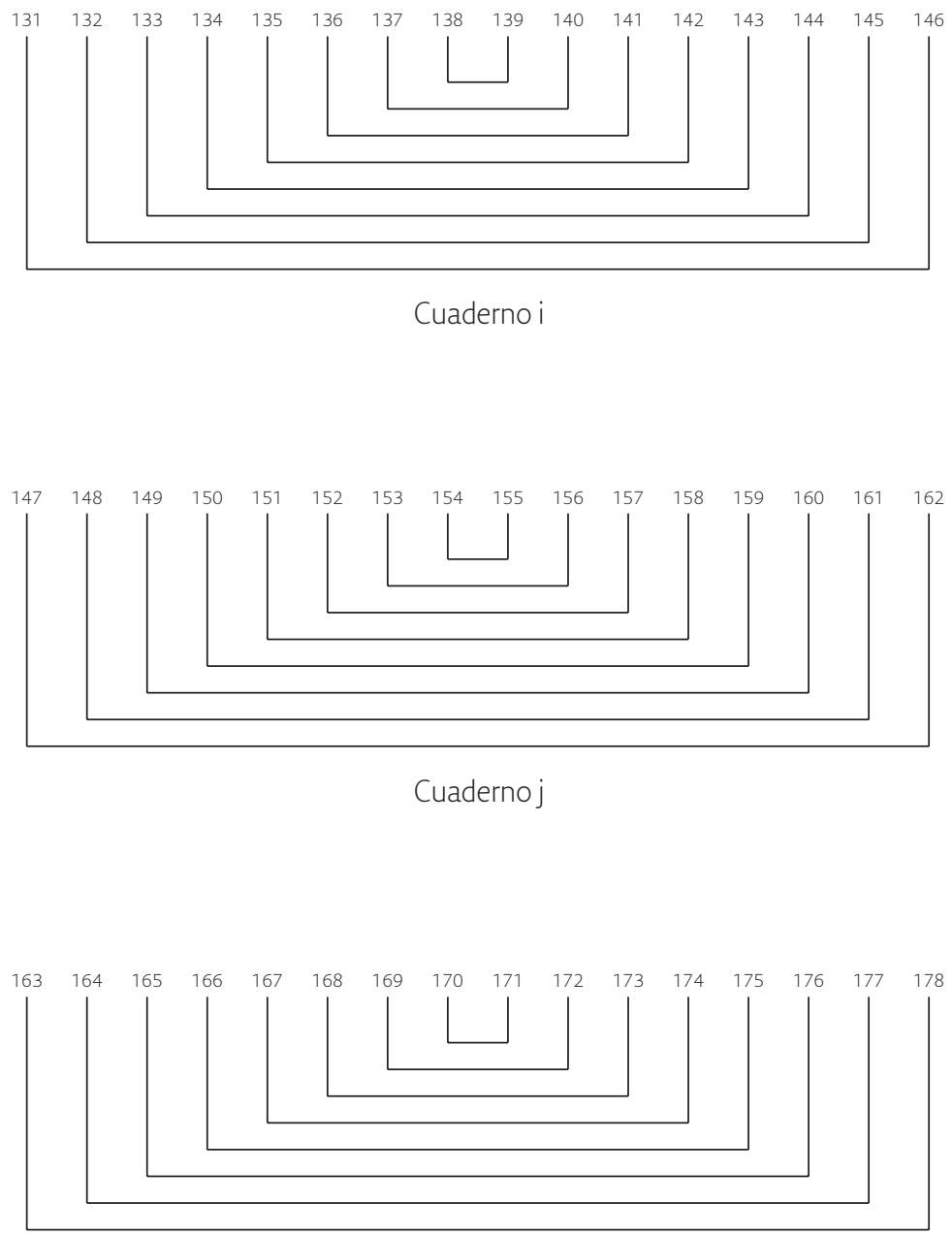

Cuadernok

RILCE 37.1 (2021): 319-46 
MARTOS. MANUSCRITOS E INCUNABLES EN TORNO A LOS REYES CATÓLICOS: CANCIONERO EM6

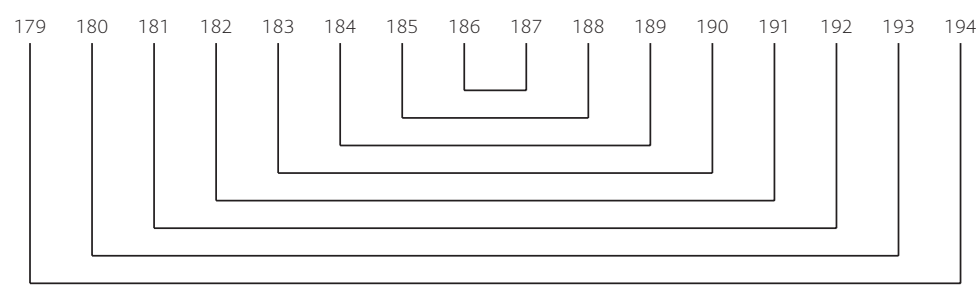

Cuadernol

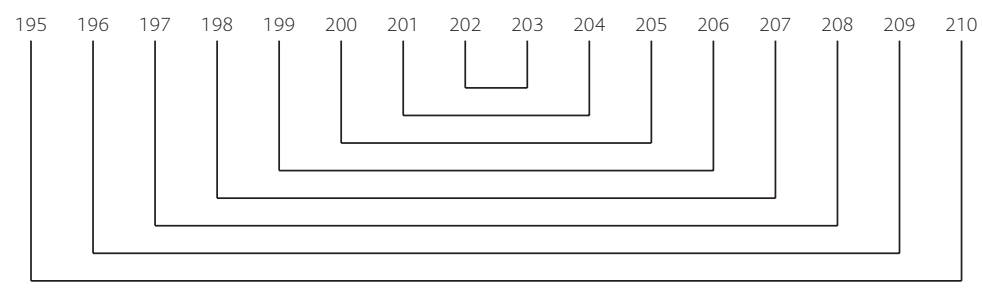

Cuaderno $m$

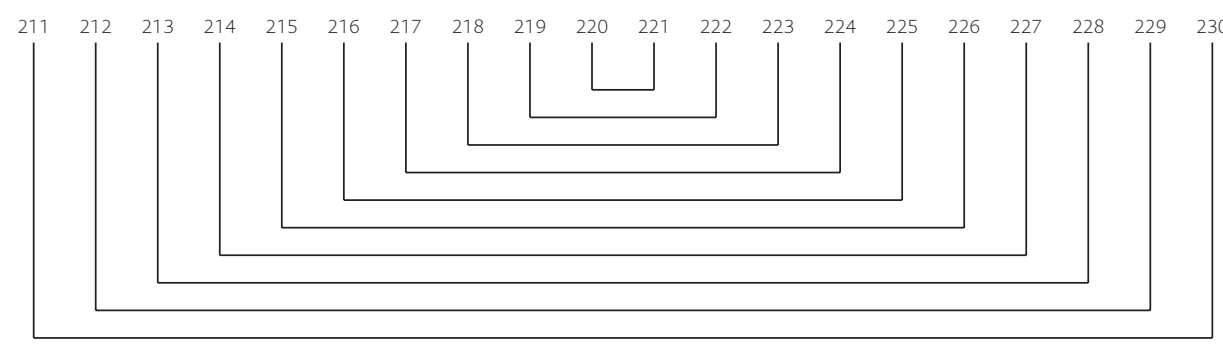

Cuaderno $n$

$232 \times \quad 233 \quad 234 \quad 235 \quad 236 \quad \times \quad \times$

Pliego suelto impreso $a$

237237 bis

Pliego suelto impreso $b$

$238 \quad 239 \quad 240 \quad 241$

Pliego suelto impreso $c$ 
MARTOS. MANUSCRITOS E INCUNABLES EN TORNO A LOS REYES CATÓLICOS: CANCIONERO EM6

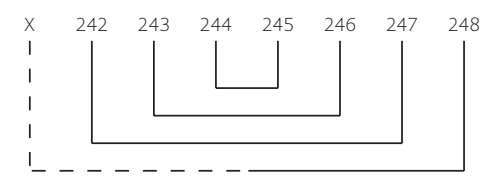

Cuaderno o

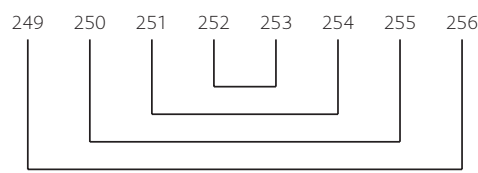

Cuaderno $p$

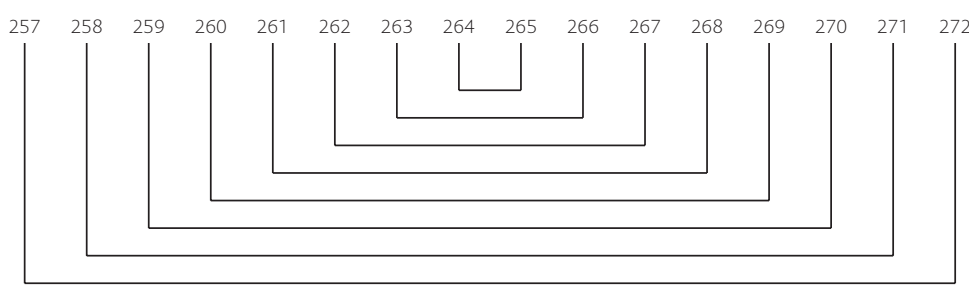

Cuaderno q

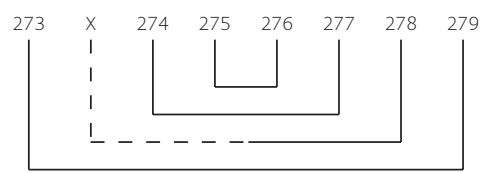

Cuaderno r

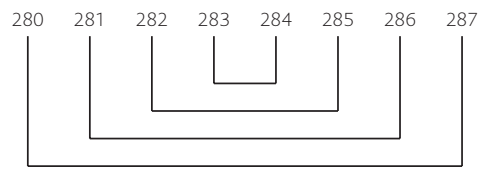

Cuadernos

RILCE 37.1 (2021): 319-46 
MARTOS. MANUSCRITOS E INCUNABLES EN TORNO A LOS REYES CATÓLICOS: CANCIONERO EM6

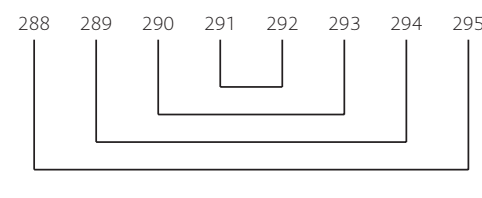

Cuadernot

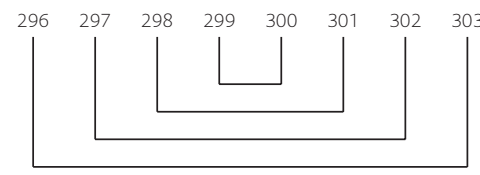

Cuaderno u 